\title{
Numerical Analysis of Geocell Protective Slope Stability
}

\author{
Guangyue Wang ${ }^{*}$, Jianpeng Zhang and Tianyu Xu
}

School of Civil Engineering, Shandong University, Jinan, Shandong, 250061, China

\begin{abstract}
Geocell protective slope is a kind of important ecological protection form, which is widely used in the geotechnical engineering field. Based on the finite element software ABAQUS, and combining with protective slope body's mechanics performance in shallow soil, the finite element model of geocell slope protection is established under the conditions of rainfall seepage, and then we simulate the shallow and the overall stability of slope in rainfall seepage cases. The results show that the safety factor of slope body increased by about $14 \%$ when using geocell slope protection and it reduces the displacement of slope surface effectively, it prolongs the destruction time of the slope under the condition of continuous reduction of soil shear strength, and it further helps reducing the collapse or part of slope sliding of slope disasters.
\end{abstract}

Keywords: Geocell; side slope; stability; safety factor.

\section{INTRODUCTION}

Rainfall is the main factor of the slope instability, the majority of instability and failure of slope is caused by the infiltration of rain and soak softening, so how to choose the form of slope protection to improve the overall stability of slope becomes the focus of the slope protection projects [1$3]$. Geocell protective slope is a compound ecological slope protection technology, which combines the geocell with the grass; it makes construction convenient and simple, and has the low maintenance charge and higher ecological and economic benefits, so it is used more and more widely in slope engineering [4-7]. We conduct a comprehensive research on engineering measures of the slope such as erosion protection, maintenance, management of disease and the environmental impact assessment of the loss of the water and soil. In addition, the rich and valuable experience and results have been achieved. For example, Ji-ru Zhang presented the calculation method of stability analysis at the base of practical knowledge and theoretical analysis of failure mode on the slope [8]. The design and calculation method of the soil slope are given by Xiao-hua Yang [9]. Guang-yue Wang provided the calculation method of the design and construction technology of the geocell [10]. And Chang-gen Yan discovered that the geocell protective slope can reduce the average erosion rate by $48 \%$ and it can also weaken the development and formation of the gully by adding the scour model test of the geocell at the loess slope [11]. However, people at home and abroad seldom use the geocell protective slope to have the integral stability analysis under rainfall conditions. Given that, in this paper, by using the finite element software ABAQUS, we simulate and analyze the enhancement effect

*Address correspondence to this author at the School of Civil Engineering, Shandong University, Jinan, Shandong, 250061, China;

Tel: (+86)0531-88392843; Fax : (+86)0531-88392843;

E-mail:wgyue@sdu.edu.cn of the slope stability when using the geocell protective slope under the condition of rainfall.

\section{THE COUPLING THEORY IN SLOPE STRESS FIELD AND SEEPAGE FIELD}

Rainwater infiltration on the slope is the main factor of the overall instability of slope, the rainfall infiltrating into the soil will flow in the soil under the condition of rain water and produces the head loss, and then the drag force on slope soil particles is formed, that is the dynamic water pressure, and the distribution of seepage field determines the distribution of dynamic water pressure state, the dynamic water pressure changes as the change of seepage field distribution, eventually it leads to the change of slope of the stress field , thus affecting the stability of the slope. The size of the dynamic water pressure is mainly affected by inner water head of the soil slope, its computation formula is as follows [12]:

$\mathrm{G}_{\mathrm{d}}=\mathrm{r}_{\mathrm{w}}(\mathrm{h}-\mathrm{z})$

In this formula, $G_{d}$ stands for dynamic water pressure, $r_{w}$ stands for the unit weight of water, $h$ stands for the water head distribution function in side slope, $\mathrm{z}$ stands for the depth of the position of calculation points in dynamic water pressure.

Before carrying on the coupling calculation in stress field and seepage field, we need to calculate the initial stress distribution before the rainfall infiltration into the slope. The surface displacement is zero before we build or excavation, but the stress of the soil exists, this point that has the stress but hasn't the displacement is called ground-stress balance point. When considering that the dead load field is the major factor in the production of ground stress field, obviously gravity is the external force. Ground stress field extracts the internal force to the numerical model, and applies gravity, makes the internal force and external force balance, and then gets a precise, without disturbance by human factors' initial 
state in numerical model. When coupling the initial stress field and seepage field, we can get the accurate reflection of the effect of rainfall infiltration on slope stability.

\section{THE IMPLEMENTATION OF FLUID-SOLID COU- PLING IN ABAQUS}

As the ABAQUS software defines the constitutive models which can response to various stress-strain relationships of the soil and the software has strong processing capacity in interface, so this paper conducts the vertical and horizontal contrastive analysis for stable situation of the geocell protective slope under the condition of rainfall infiltration by using ABAQUS and combining with the strength reduction method. We calculate the stress field of the slope only under the action of gravity, and the stress is applied to each node of the model, then we get the initial state with stress, but there is no displacement in it, finally we couple the seepage field again. We can use the surface pore fluid loading of ABAQUS software to define the infiltration intensity and simulate the process of rainfall infiltration on slope model.

\section{THE SOLID MODEL IN FINITE ELEMENT OF ABAQUS}

\section{Modeling}

The geocell protective slope simulated in this paper is the homogeneous soil slope, the slope angle in the slope model is $35^{\circ}$, the overall height of side slope is $9 \mathrm{~m}$, the slope height is $6 \mathrm{~m}$,the deep length is $17 \mathrm{~m}$, the constitutive model in the rock-soil mass uses Mohr-Coulomb model. The type in the geocell is SB200 $\times 400 \times 1.5-8$, the sheet chooses grain surface, the peel strength of the welding spot is $1000 \mathrm{~N} /$ $10 \mathrm{~cm}$, the thickness is $1.5 \pm 0.1 \mathrm{~mm}$, the height is $200 \mathrm{~mm}$. The welding distance is $400 \mathrm{~mm}$, which attaches $8 \mathrm{~mm}$ punching.

The calculating parameters of the model of the geocell protective slope are summarized in Table $\mathbf{1}$.

\section{Mesh Dividing}

The material structure of geocell is very special, which uses sheet welding, so the geocell uses shell element--S4R, the whole geocell divides into 960 units. For the slope soil section, because it involves the rainfall infiltration of the soil, we use the hexahedral element--C3D8P, which possesses pore pressure degree of freedom. This kind of element has eight degrees of freedom (including pore pressure degree of freedom), the soil slope is divided into 26530 units. In order to make the calculation of the model easy to convergence when simulating the numerical calculation, the continuous medium model in which soil and the shell element of geocell has the same nodes but varies in nature of the mate-

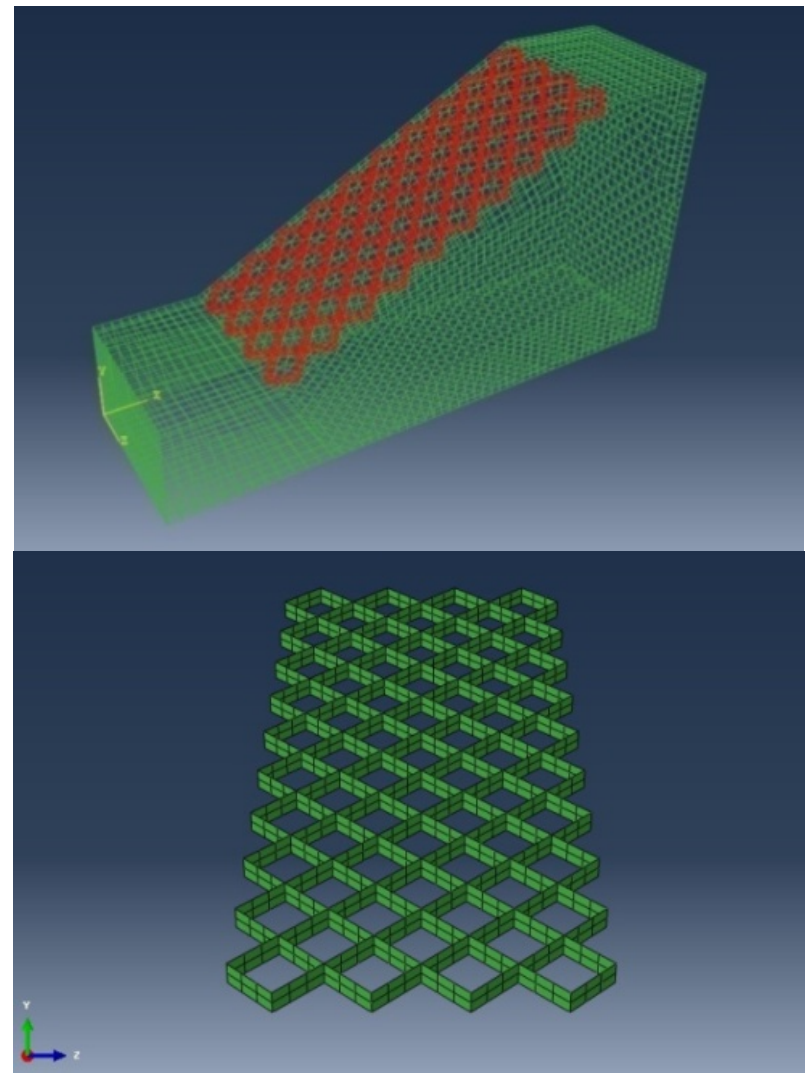

Fig. (1). The picture of mesh dividing.

rial is adopted. The whole model has a total of 29630 nodes, 27490 units. The mesh dividing of the model is shown in Fig. (1).

\section{Boundary Conditions}

For the model boundary conditions, because the model is taken as part of the overall slope to analyze, the boundary is defined as:

(1) Limit the degree of freedom of the normal direction of front facade, behind facade, left facade, right facade.

(2) Limit the degree of freedom of three directions for $\mathrm{x}, \mathrm{y}, \mathrm{z}$ at the bottom of the model at the same time.

(3) We set the boundary conditions of the static water pore pressure that have a linear increase with depth below the water level of front façade and behind façade of the slope. The bottom, the front facade and behind facade sets the undrained boundary condition. In this way, it could make the numerical model have a maximum approach to the practical engineering. The boundary conditions of pore pressure are shown in Figs. $(2,3)$.

Table 1. Calculating parameters of Slope model

\begin{tabular}{|c|c|c|c|c|c|c|}
\hline Material & $\begin{array}{c}\text { Elasticity } \\
\text { Modulus }\end{array}$ & Poisson's Ratio & Cohesive Force & Mocha Angle & $\begin{array}{c}\text { Pry Density } \\
\text { Coefficient }\end{array}$ \\
\hline \hline Soil & 30 & 0.3 & 37 & 23 & 1.78 \\
\hline Geo-cell & 500 & 0.25 & -- & -- & -- \\
\hline
\end{tabular}




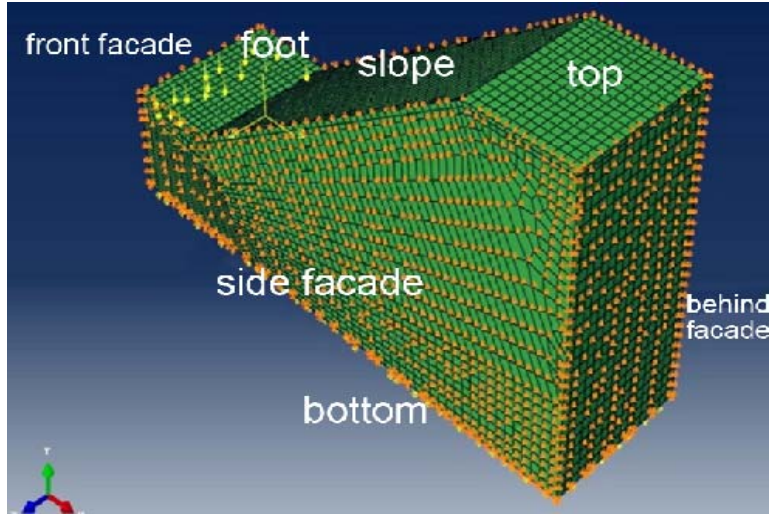

Fig. (2). Boundary sketch.

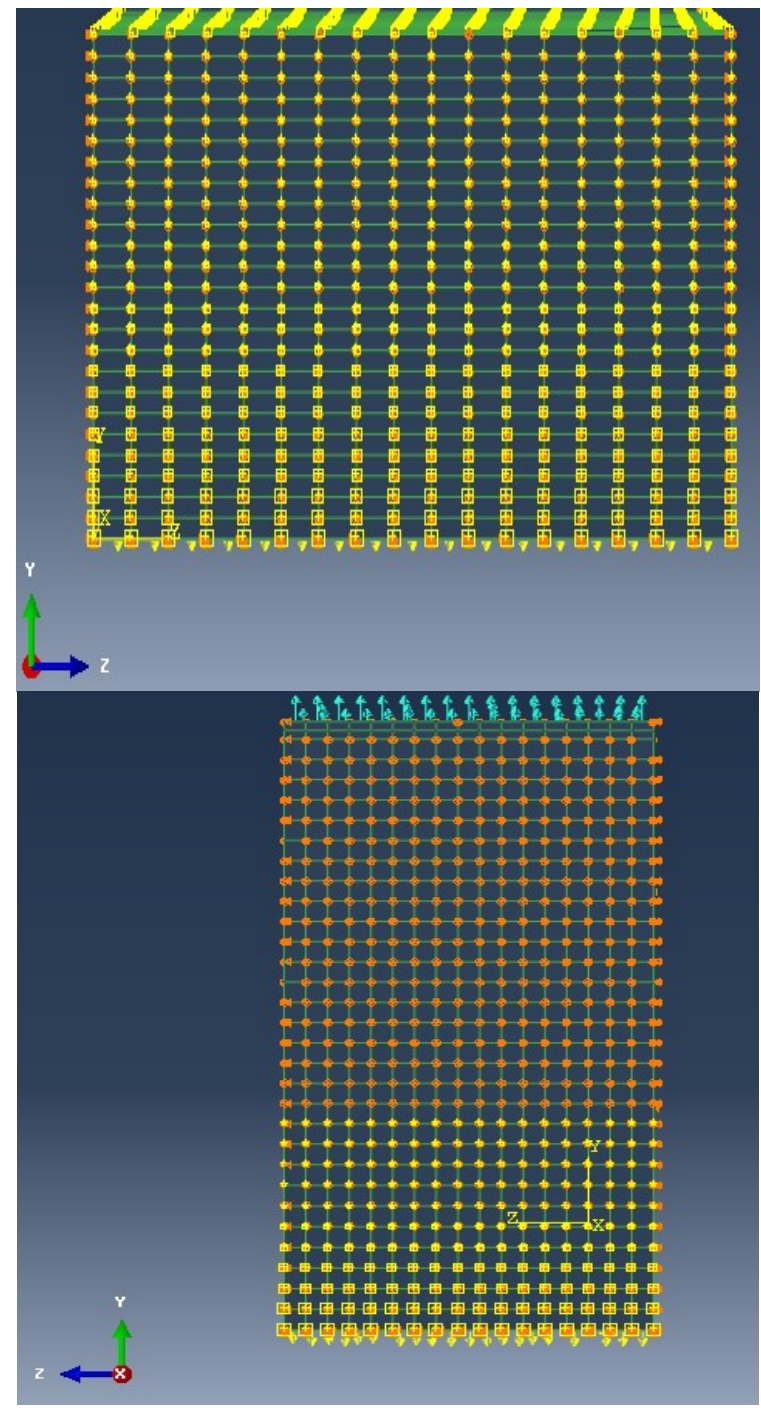

Fig. (3). Boundary conditions of pore pressure in front facade, behind façade

\section{The Calculation of the Initial Stress}

We need to get the initial stress distribution of the slope before the analysis of rainfall infiltration. The surface displacement is zero before we build or excavation, but the stress of the soil exists, the point-in-time that has the stress but there is no displacement in it is the balance point of ground-stress. The balance point of ground stress is to make the numerical model have a state that exists initial stress but there is no initial strain in it. When considering that the gravity field is the major factor in the production of ground stress, obviously the gravity is the external force. The ground stress field is the initial state of numerical model that extracts the internal force to exert on the numerical model, and applies the gravity in order to make internal force and external force balance. Then we get the more precise initial state, which has not the disturbance caused by human factors. In the definition of initial ground stress, it needs to satisfy the following two basic conditions at the same time:

(1) Stress equilibrium conditions: We should make the equivalent node load formed in the stress field and the external force formed under the action of external load balance. If the equilibrium conditions cannot be met, we would not be able to get an initial state where the displacement is zero, and the stress field would not be the initial stress field that was initially imposed.

(2) Yield conditions of the model: If we use gauss point to define the initial stress directly, there will be always some stress that is greater than gauss points of the yield surface existing in the initial stress field. Although the stress beyond the gauss points of yield surface can go by the stress transfer and it can be adjusted in the later calculation process, appearing this kind of circumstance is not reasonable. If the stress beyond the yield surface appears in large numbers, a lot of iterations will be needed to transfer the stress. In this way, it not only increases the difficulty of calculation, but also will cause the result not converge.

Based on the above two basic conditions, balancing the initial stress is very necessary. The method used in this article is to impose the gravity load, and define the appropriate boundary conditions according to the actual situation of the project. We can get the initial stress under the gravity loads by calculating, and then apply the initial stress and gravity load to the initial finite element model. In this way, it assures the balance of initial ground stress, and the results can be achieved in the later calculation process, in addition, it is more accurate.

The initial stress distribution where the ground stress equilibrium was carried out on the slope is shown in Fig. (4) and the initial vertical displacement which is under the action of gravity of the whole slope is shown in Fig. (5).

\section{THE ANALYSIS OF COMPUTING RESULT}

\section{The Analysis in Protecting Effect of the Geocell}

In order to comparatively study the protecting effect that the geocell applies to the side slope, this paper simulates the stable situations of geocell in protective slope and no protective slope at the different infiltration intensity. The calculation results summarized in Table 2 .

Comparing to safety factor under the condition of the same rainfall intensity, we can conclude that in the same intensity under the action of rainfall infiltration, comparing the protecting slope that has geocell with the slope without protecting, the safety factor value all increases. And we 


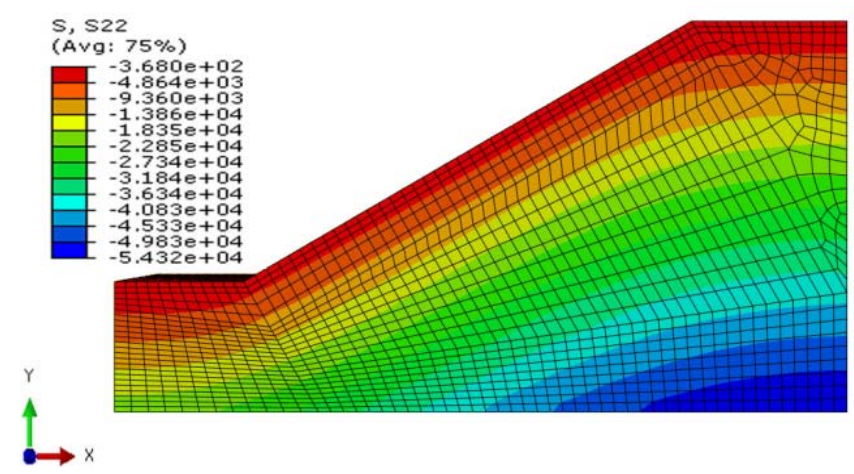

Fig. (4). The vertical effective stress distribution-S22.

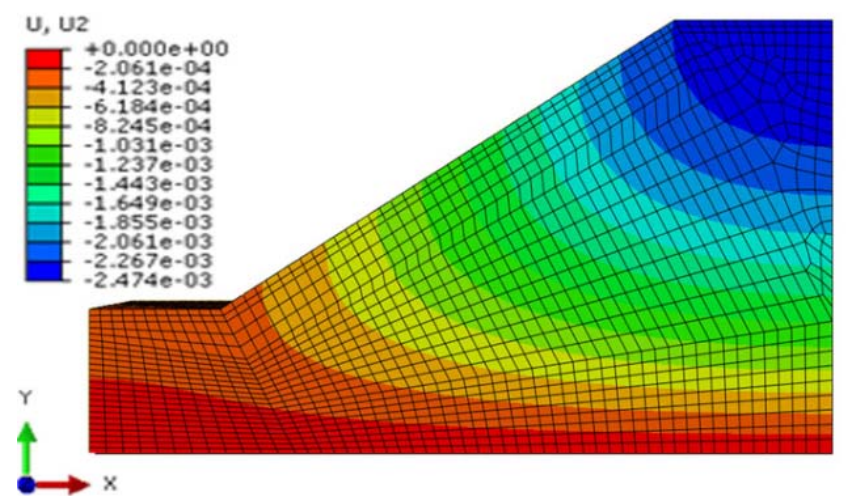

Fig. (5). Initial displacement under gravity-U2.

know that for both high intensity rainfall infiltration and little rainfall for a long time, the geocell material can improve the whole slope stability obviously.

Through the comparative analysis of the displacement results in Fig. (6), we can conclude that the total displacement of protective slope of the geocell is obviously lower than the side slope of pure soil under the same reduction factor. As the reduction factor becomes increasing, the two kinds of slope protection appear larger displacement mutation at the bottom of the slope, eventually it leads to the overall instability of slope surface. But comparing with unprotective slope, the protective geocell reduces the extreme displacement nearly 13\%. And therefore, the geocell can reduce the extreme displacement of slope surface effectively by using its own strength. In addition, it can limit the local displacement increases suddenly and strengthen the integrity

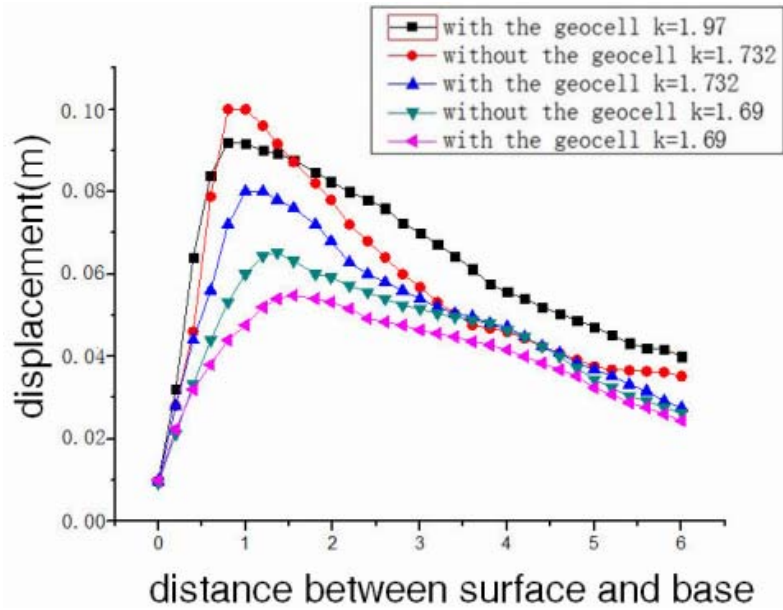

Fig. (6). The displacement curve of Slope.

of slope surface, thus it can prevent the slope instability that caused by local failure, and improve the stability of the slope. According to Fig. (7), we can see that the geocell has a delayed effect on slope failure before appearing the turning point of the displacement (the point of slope failure). That is to say, the geocell prolongs the destruction time of the slope under the condition of continuous reduction of shear strength. These facts show that the geocell material has an obvious strengthen effect on the slope stability.

According to cloud picture about displacement in Figs. $(\mathbf{8}, \mathbf{9})$, we can clearly judge the overall instability of slip surface of the slope. Though the geocell protective slope also appeared the sudden increase in displacement near the bottom under the same reduction factor and caused overall instability, the protective geocell reduces the displacement nearly $13 \%$ when comparing with unprotective slope. As we can know from displacement curve when the geocell protective slope is damaged, we can know that the geocell effectively limits the maximal displacement and it can control the relatively homogeneous distribution of the displacement along the slope surface. So we conclude that the geocell can make use of its strength to reduce the extreme displacement of the slope surface, control the sudden increase of the local displacement and strengthen integrity of the slope surface. And therefore, it can prevent the instability resulted from local failure, improve the stability of the slope. As the analysis of the data shows, the bottom is the weak part of the

Table 2. The Safety Factor of the Working Conditions

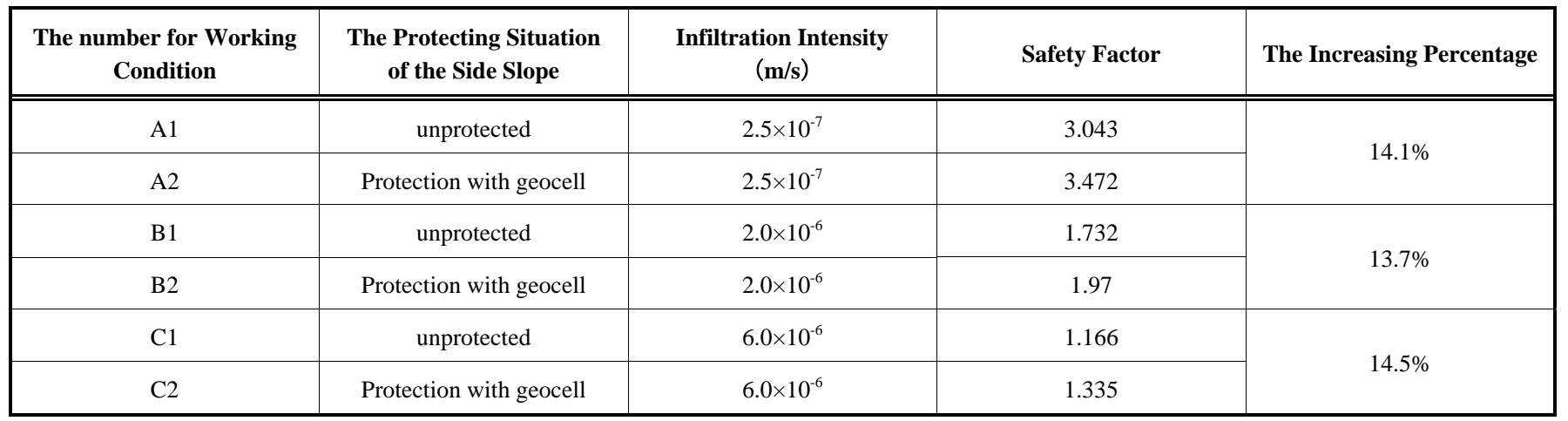




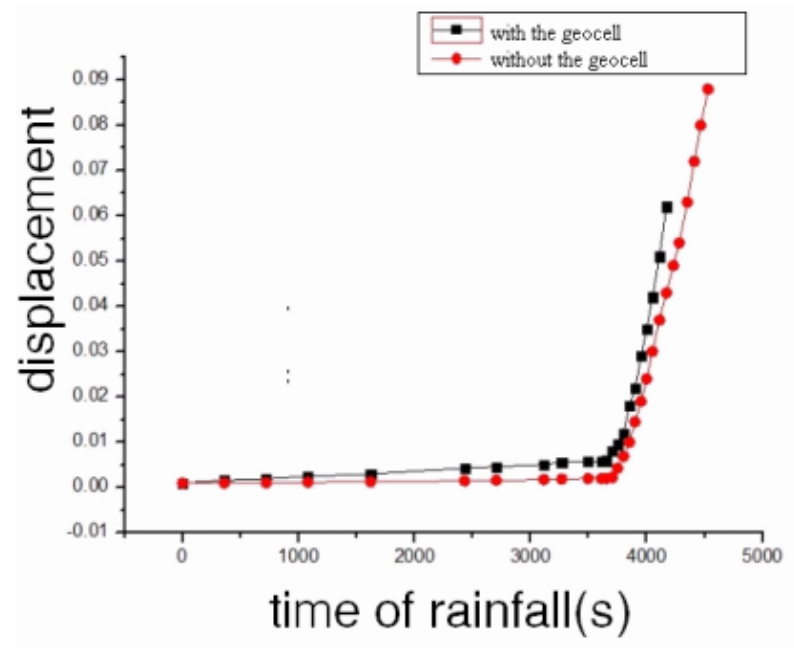

Fig. (7). Displacement changes with time of the point.

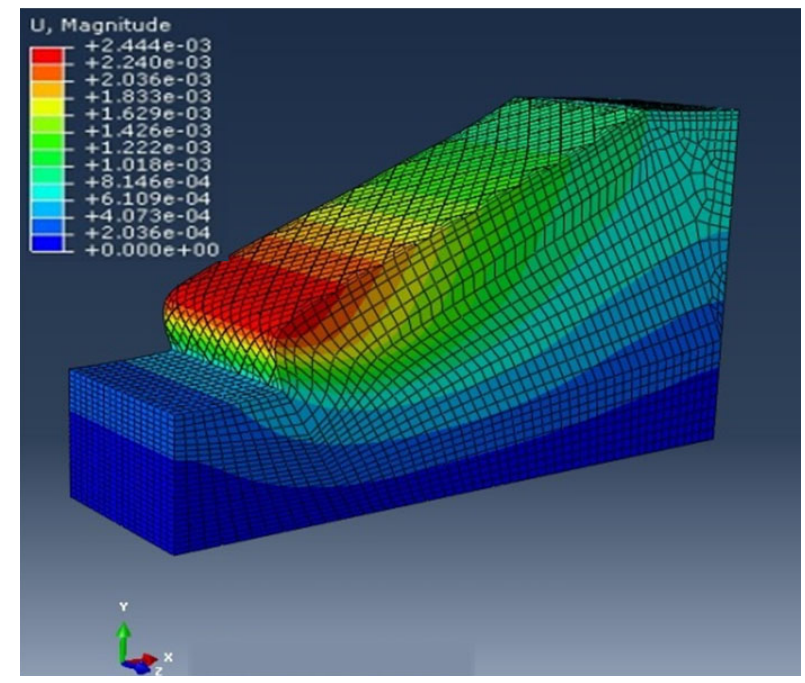

Fig. (8). The cloud picture without protective slope

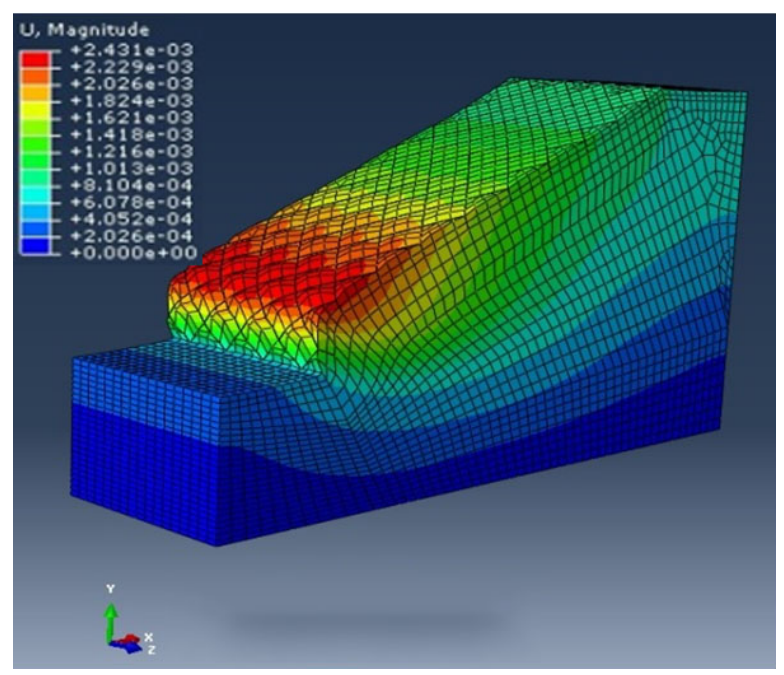

Fig. (9). The cloud picture with the geocell

slope, we should strengthen the fixing or increase the quantity of anchor.

\section{The Change Law in Plastic Strain}

When the slope soil is under the rain load and the damage occurs, the node displacement will increase, and the slope soil will produce the shear plastic strain. The plastic strain is also an important indicator of the slope stability. We can see two groups of contrast of the plastic stain in the same time from Figs. $(\mathbf{1 0}, \mathbf{1 1})$. These two pictures also show the plastic strain of the soil protective slope and the geocell protective slope at the same time and reduction strength. The reduction factors of the two kinds of protective slope are both 1.248 when the time is $2430 \mathrm{~s}$. And the reduction factors are both 1.508 when the time is $3114 \mathrm{~s}$. It is obvious that the plastic strain zone of the unprotective slope is larger than the geocell protective slope according to the Fig. (12). And the plastic strain without protecting is intensive and widespread. From the cloud picture of the plastic zone in different protecting conditions and the same reduction factor, we can know that the geocell has a protective effect on the soil unit. Because of the effect in friction resistance between the geocell sheet and the soil, the plastic strain of the soil in geocell unit is controlled effectively and there is almost no plastic strain around the soil in geocell material. The extreme value in equivalent plastic strain of the unit center is much less than the extreme value in unprotective slope at the same po-

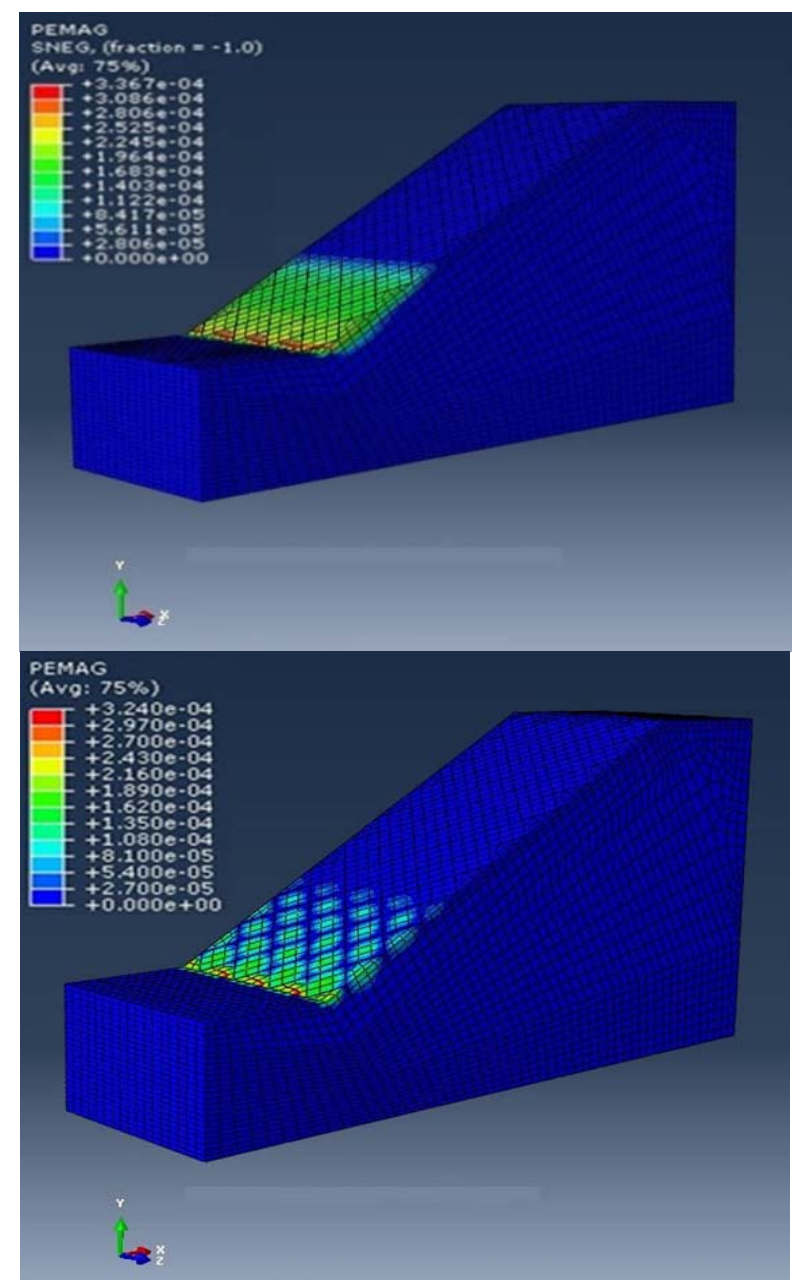

Fig. (10). The contrastive cloud picture of plastic strain in unprotecting and protecting $(\mathrm{t}=2430 \mathrm{~s})$. 

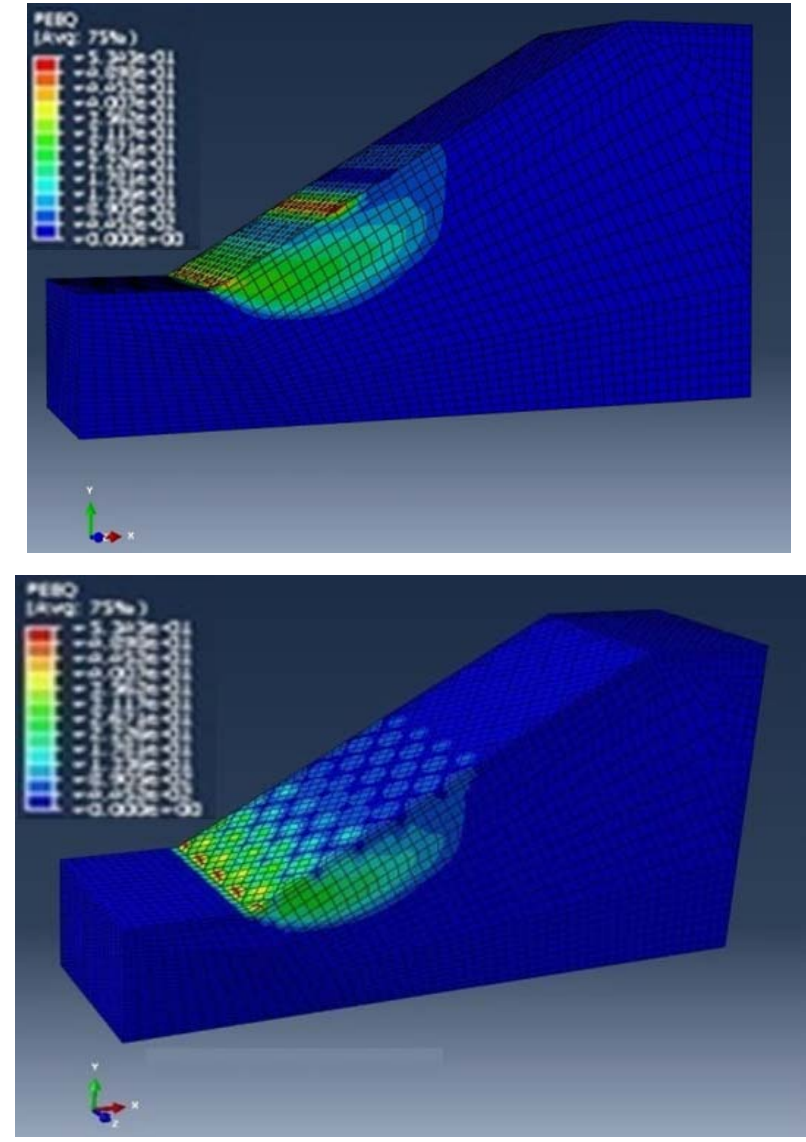

Fig. (11). The contrastive cloud picture of plastic strain in unprotecting and protecting $(\mathrm{t}=3114 \mathrm{~s})$.

sition. Through the contrastive analysis of the plastic zone, we can conclude that the protective effect is very obvious when using the geocell.

According to the strain curve in Fig. (13), we know that two kinds of protective slope appear to the sudden increase of the plastic strain at the foot of the slope after a period of rainfall infiltration. With the further increase of rainfall time, the growth of the plastic strain of the unprotective slope is greater than the geocell protective slope, it means that the unprotective slope is easier to be damaged, and the time from plastic mutation to destruction is short. Through the analysis of the plastic strain of slope, we can conclude that the geocell can enhance the slope stability effectively, strengthen the resistance performance to rainfall infiltration and delay the destruction of the slope.

\section{The Stress Distribution Characteristics of the Geocell}

The stress calculation results of the geocell are as follows:

According to the cloud picture of the stress and deformation and the stress strain curve in Figs. (14-17), we learn that when the geocell applies to the slope protection, the deformation is the biggest at the foot of the slope as well as the stress. And its stress values are several times as the stress of the top of the slope. So we should focus on strengthening the
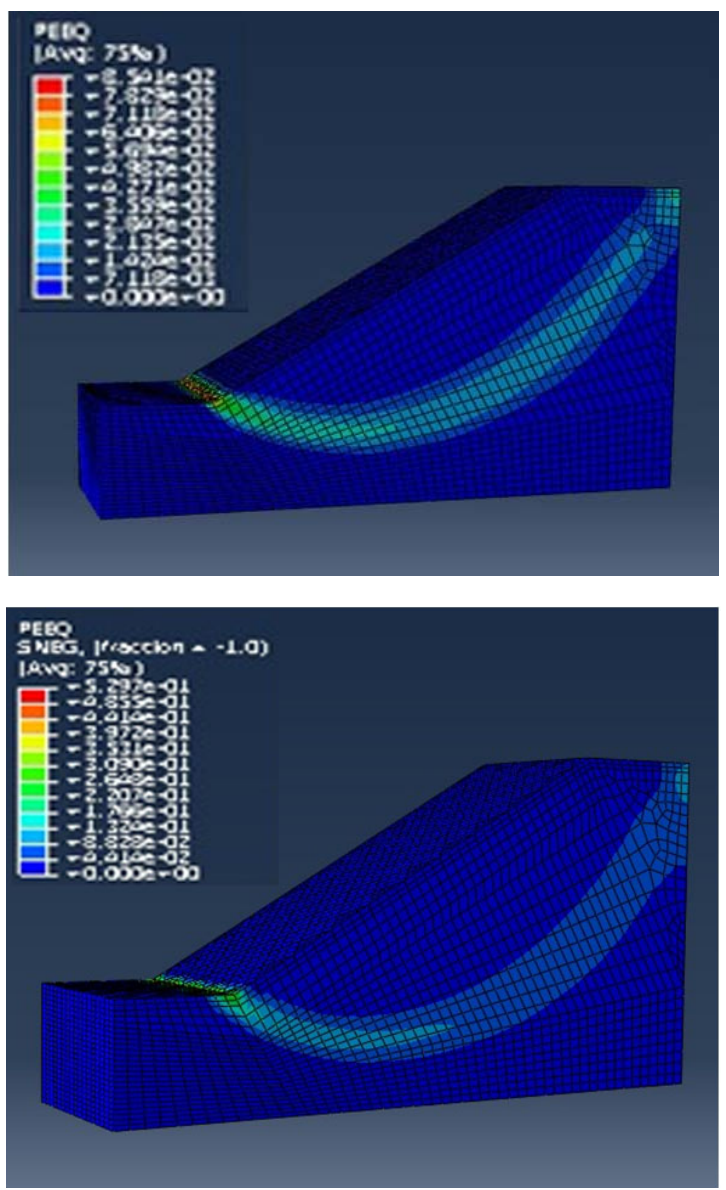

Fig. (12). The contrastive cloud picture of plastic strain in slide slope.

geocell at the foot of the slope in practical slope engineering and make the protective effect get the maximum play.

The influence that elasticity modulus of the geocell material has on protective effect. As the geotechnical material enhances the intensity of the slope surface, the geocell has the protective effect on the slope .It also strengthen the integrity of the slope at the same time. And then the geocell protective slope makes the performance that resists the rain wash and local landslide improved. So the influence of protecting effect about the geotechnical material is a problem that the engineers are very concerned about. Figs. (18-21) can tell us the change law that slope stress and safety factor changes with the elastic modulus of the geocell. And the pictures also show us that the elastic modulus of geocell has little effect on slope stress, but the elasticity modulus of the geocell has the certain effect on the stability of the slope. As the elastic modulus increase gradually, safety factor also increases accordingly, but when the elasticity modulus reaches $600 \mathrm{MPa}$, the safety factor tends to be stable. As a result, we can conclude that the elasticity modulus of the geocell material has the certain effect on the protection and the stability of slope will reinforce as the elastic modulus increases, but the effect on safety is so small that can be ignored when the elasticity modulus reaches over 600MPa. 


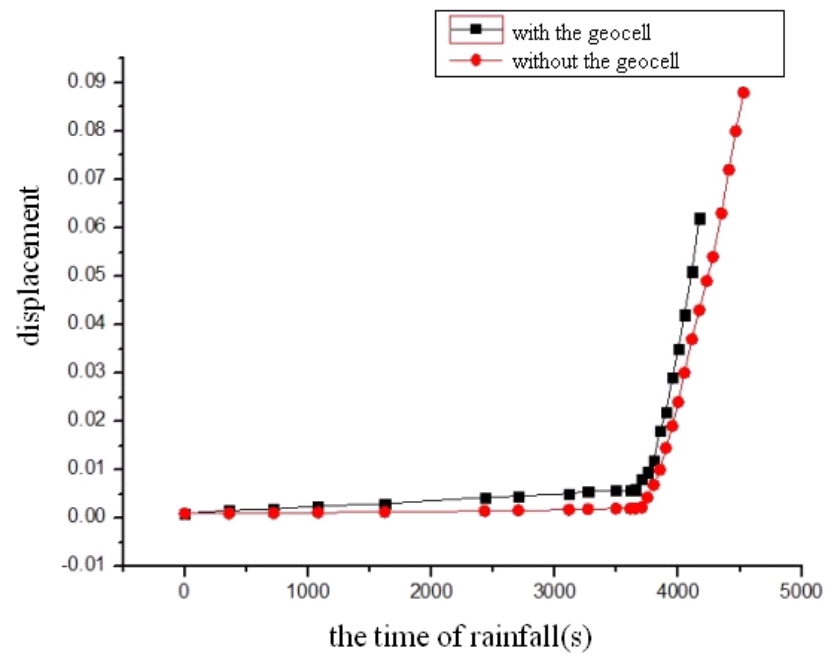

Fig. (13). Plastic strain along with the change of rainfall time.

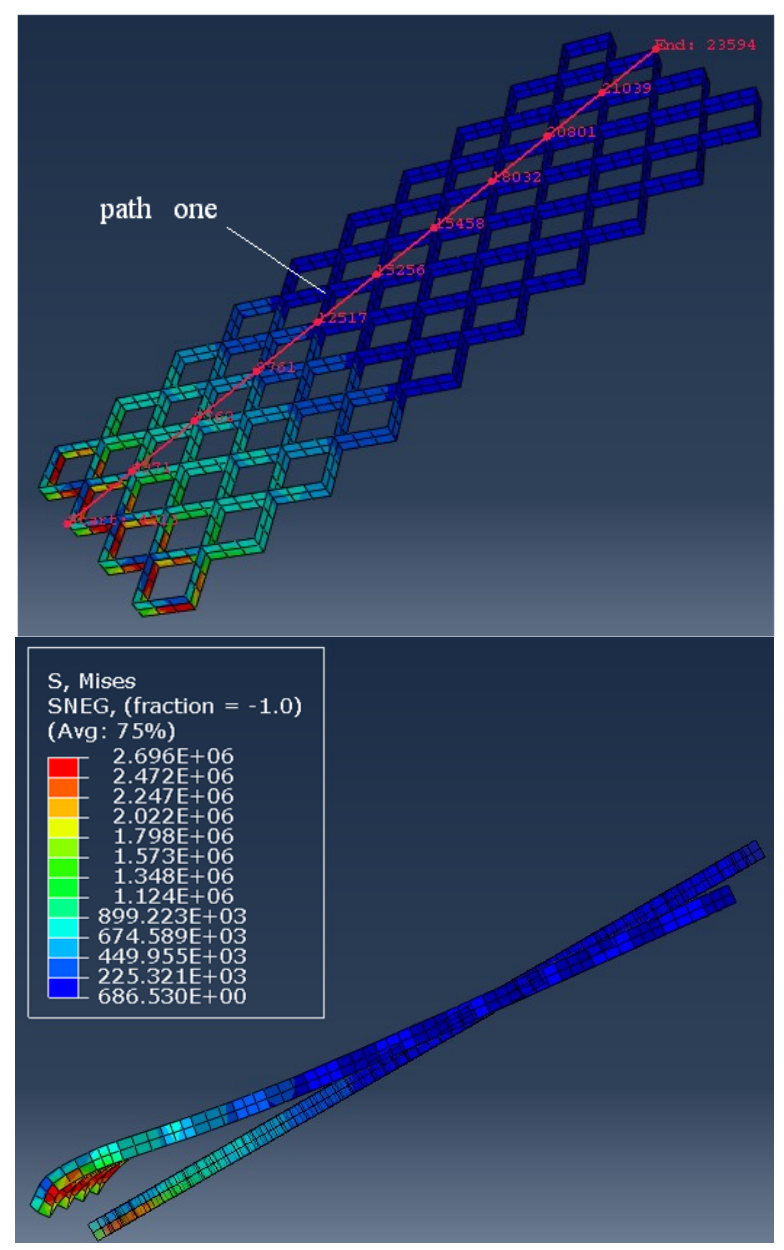

Fig. (14). The contrastive cloud picture in deformation of the geocell.

\section{SUMMARY}

1. Using the geocell to protect slope can improve its overall stability obviously, and can reduce the displacement of slope surface effectively. In addition, it can limit the sudden increase of local displacement,

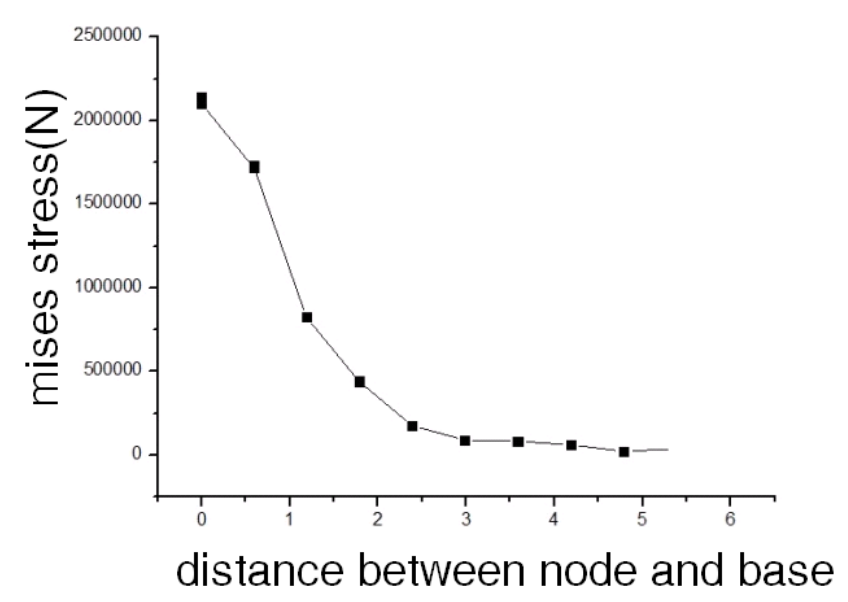

Fig. (15). Mises stress curve of the node in path one.

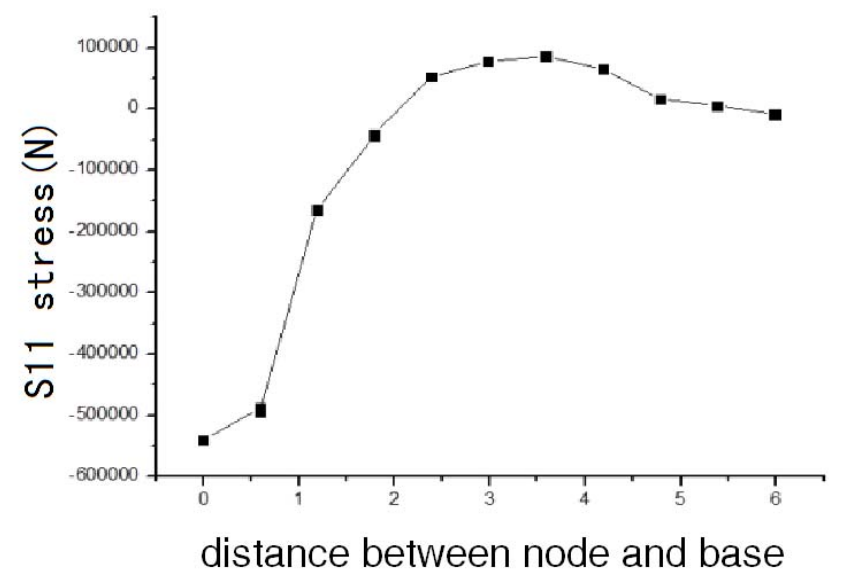

Fig. (16). S11 stress curve of the node in path one.

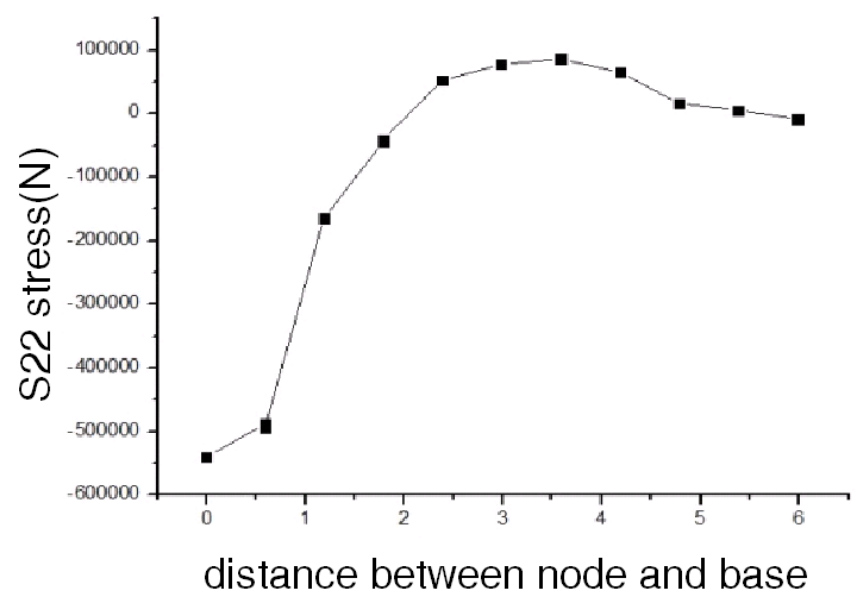

Fig. (17). S22 stress curve of the node in path one.

and then it prevents the slope instability from the local damage. And the geocell can prolong the destruction time of the slope under the condition of continuous reduction of shear strength, then enhancing the security. 


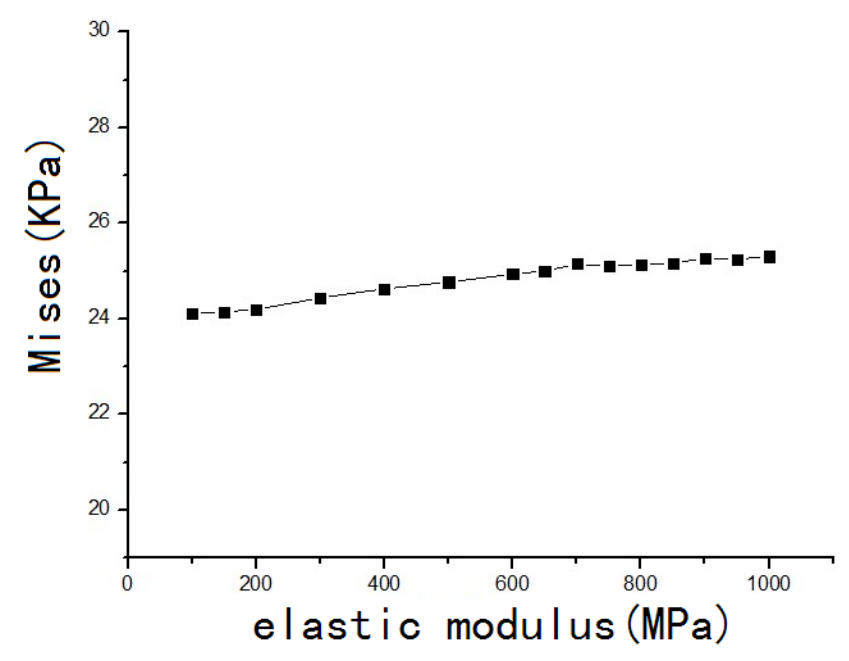

Fig. (18). Mises stress curve changes with elasticity modulus

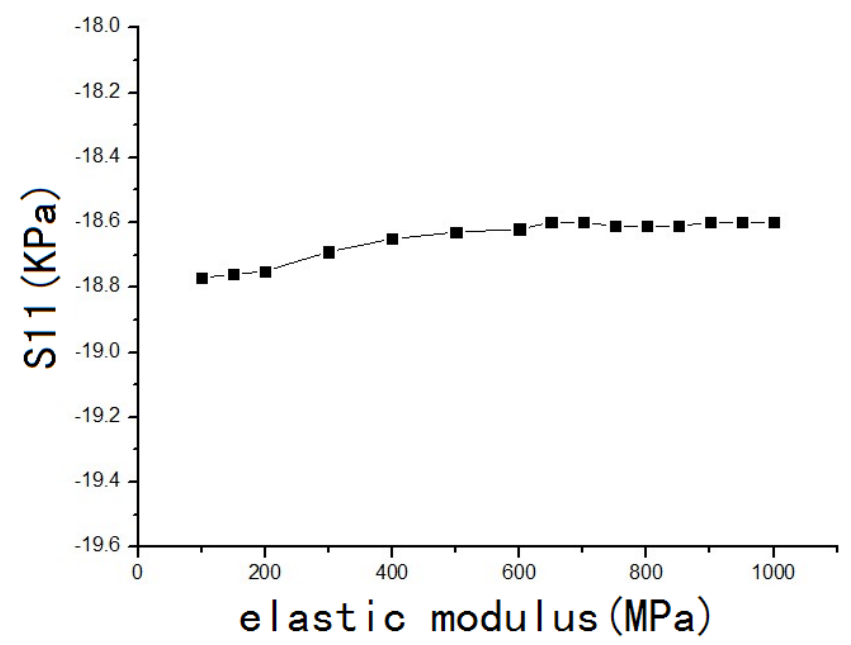

Fig. (19). S11 stress curve changes with elasticity modulus

2. When the geocell protective slope is under the action of rainfall infiltration, the geocell materials are subject to the biggest stress at the bottom of the slope. At that time it is very easy to produce the deformation and failure, it is also the weak part of protective system. So we should strengthen the anchoring in the process of construction so that the role of geocell can be played to the largest extent.

3. The elasticity modulus of the geocell has the certain effect on protecting the slope, and the effect will reinforce when the elasticity modulus increases. And the protective effect tends to be stable when the elasticity modulus reaches over $600 \mathrm{MPa}$, then the influence can be neglected.

\section{ACKNOWLEDGEMENTS}

This project was supported by the National Natural Scien ce Foundation of China (Grant No.11072133).

\section{REFERENCES}

[1] S-Y. Chen. "A Method of Stability Analysis Taken Effects of Infiltration and Evaporation into Consideration for Soil Slopes", Rock and Soil Mechanics, vol. 18, no. 2, pp. 8-12, 1997.

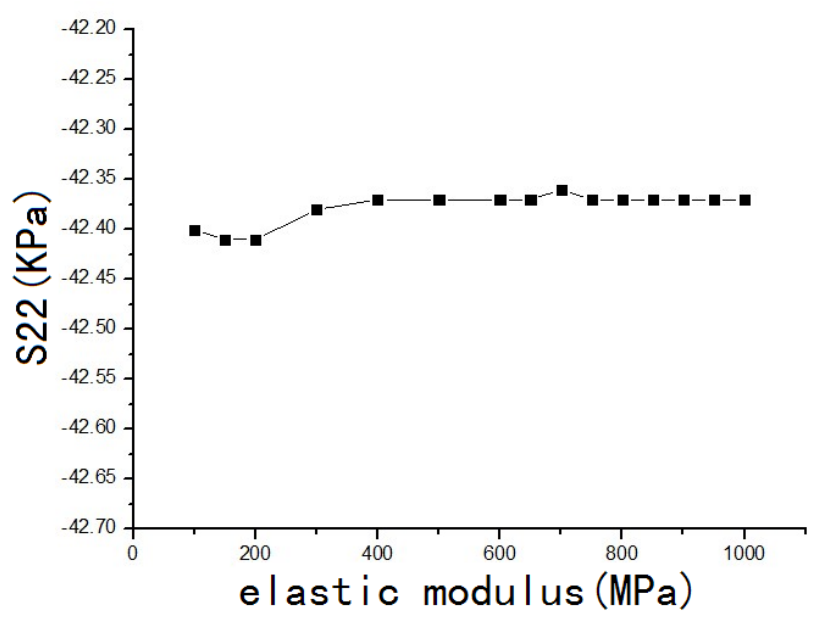

Fig. (20). S22 stress curve changes with elasticity modulus.

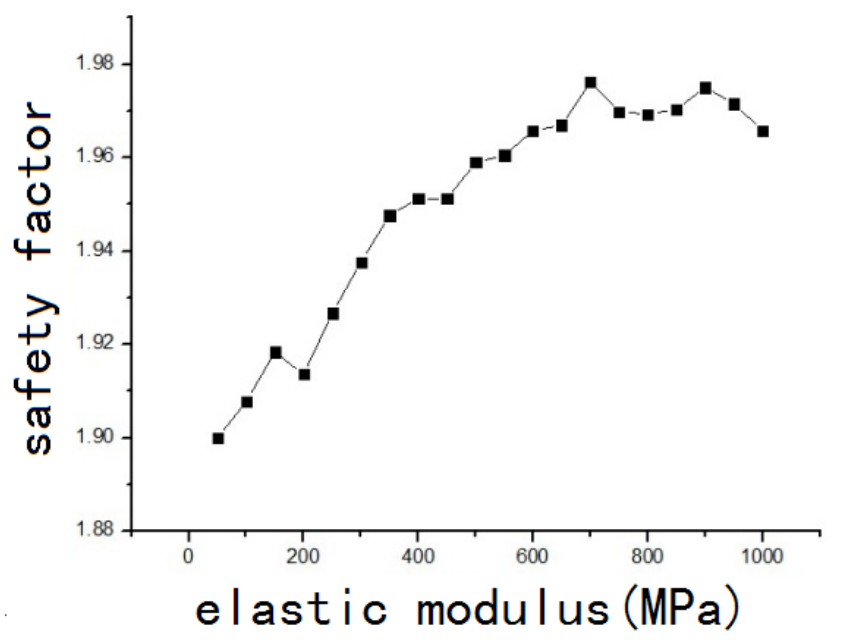

Fig. (21). Safety factor changes with elasticity modulus.

[2] J. M. Gasmo, H. Tahardjo, E. C. Leong, "Infiltration Effects on Stability of a Residual Soil Slope", Computers and Geotechnics, vol. 26, no. 2, pp. 145-165, 2000.

[3] S-X. Chen, S-Y. Chen. "Analysis of Stability of Unsaturated Soil Slope Due To Permeation of Rainwater”, Rock and Soil Mechanics, vol. 22, no. 4, pp. 447-450, 2001.

[4] G-W. Li, "the Application of Highway Slope in Expansive Soil Area about Slope Vegetation of the Geocell”, Highway Traffic Science and Technology(Application Version), vol. 28, no. 4, pp. 4648, 2008.

[5] X-M. Lu, "The Application of Protective Slope in Carbonaceous Mudstone of one Highway about the Geocell”, Shan Xi Architecture, vol. 34, no. 1, pp. 295-297, 2008.

[6] Z-Y. Zhang, C-X. Li, Z-J. Liang, “The Application of Protective Slope in Barren Soil of one Reservoir about the Geocel”, Pearl River, vol. 2005, no. 2, pp. 35-36, 2005.

[7] X-H. Zeng, "The Application in the Excavation of the Slope about the Geocell”. Shan Xi Architecture, vol. 37, no. 9, pp. 87-88, 2011.

[8] R-R. Zhang, R-S. Zhu, X-Q. Cheng, "The Application of the Stability Analysis in Erosion of Rock Slope Vegetation about the Geocell”, Rock Mechanics, vol. 34, no. 3, pp. 359-362, 2003.

[9] Xiao-hua Yang, Wen-sheng Wang, "The Application of Protective Slope in Loess Highway about the Geocell”, Road, vol. 36, no. 8, pp. 179-182, 2004.

[10] G-Y Wang, Y-S. Wang, J-S. Yang, “The Application of Protective Slope about the Geocell”, Water and Soil Protection in China, vol. 41, no. 2, pp. 33-34, 2003. 
[11] C-G. Yan, X-h. Yang, Y-l. Xie, J-C. Li, “The Experimental Study of the Resistance to Erosion in Loess Embankment about the Geocell”, Rock Mechanics, vol. 36, no. 8, pp. 1332-1344, 2005.
[12] C-Z. Xiao, Y-R. Li, "The Stability of Numerical Analysis of Protective Grassing Slope in Three-Dimensional Gauze Pad”, Chang Jiang River, vol. 42, no. 9, pp. 76-80, 2011.

(c) Wang et al.; Licensee Bentham Open.

This is an open access article licensed under the terms of the Creative Commons Attribution Non-Commercial License (http://creativecommons.org/licenses/by-nc/3.0/) which permits unrestricted, non-commercial use, distribution and reproduction in any medium, provided the work is properly cited. 